\title{
Ultrasonic Transducers for Harsh Environments
}

\author{
J. Daw, B. Tittmann, B. Reinhardt
}

November 2016

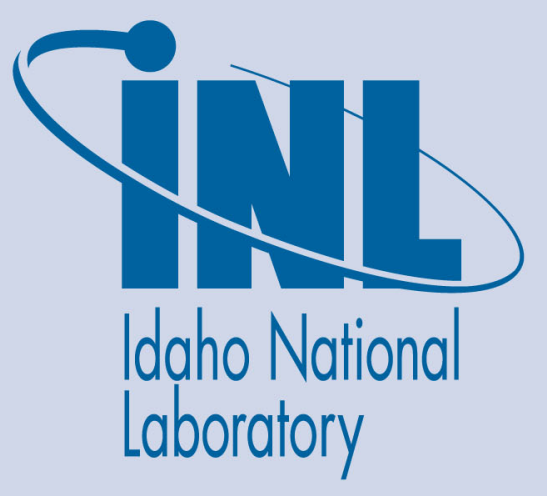

The INL is a U.S. Department of Energy National Laboratory operated by Battelle Energy Alliance 


\title{
Ultrasonic Transducers for Harsh Environments
}

\author{
J. Daw, B. Tittmann, B. Reinhardt
}

November 2016

Idaho National Laboratory Idaho Falls, Idaho 83415

http://www.inl.gov

Prepared for the

U.S. Department of Energy

Under DOE Idaho Operations Office

Contract DE-AC07-05ID14517 


\title{
Ultrasonic Transducers for Harsh Environments
}

\author{
B. Reinhardt*, J. Daw ${ }^{+}$and B. Tittmann*, \\ Penn State University, University Park, PA 16802 \\ Idaho National Laboratory, Idaho Falls, Idaho
}

Abstract-The Pennsylvania State University (PSU) was awarded an Advanced Test Reactor National Scientific User Facility (ATR NSUF) project to evaluate the performance of promising magnetostrictive and piezoelectric transducers in the Massachusetts Institute of Technology Research Reactor (MITR). Four piezoelectric transducers with Aluminum Nitride (AlN), Zinc Oxide (ZnO), and Bismuth Titanate (BiTi) as the active elements and two magnetostrictive transducers were fabricated with Remendur and Galfenol as the active elements. The irradiation was for 18 months with an integrated neutron fluence of approximately $8.68 \mathrm{E}+20 \mathrm{n} / \mathrm{cm}^{\wedge} 2$ for $\mathrm{n}>1 \mathrm{MeV}$, temperatures in excess of $420^{\circ} \mathrm{C}$, and a gamma fluence of $7.23 \mathrm{~Gy} / \mathrm{cm} 2$. The sensor performance is explained in the context of the pulse-echo signals. The feasibility of ultrasonic transducers in a nuclear reactor has been established. This opens the door to leave-in-place sensors for in-reactor conditions and materials.

Index Terms - Ultrasonic Transducers, harsh environment, Nuclear reactor radiation, piezoelectrics, magnetostriction.

\section{INTRODUCTION}

S EVERAL DOE-NE programs, such as the Fuel Cycle Research and Development (FCRD) [1], Advanced Reactor Concepts (ARC) [2], Light Water Reactor Sustainability (LWRS) [3], and Next Generation Nuclear Power Plants (NGNP) programs [4,5], are investigating new fuels and materials for advanced and existing reactors. A key objective of such programs is to understand the performance of these fuels and materials during irradiation. The development activities are focused upon addressing crosscutting needs for DOE-NE irradiation testing by providing higher fidelity, real-time data, with increased accuracy and resolution from smaller, compact sensors that are less intrusive [6]. The NEET ASI has established the Ultrasonic Transducer

This work was supported in part by the U.S. Department of Energy under Grant from the Advanced Test Reactor National Scientific User Facility (ATR NSUF). Brian Reinhardt, Penn State University, nairbt85@gmail.com, 973862-8155; Joshua Daw, Idaho National Laboratory, Joshua.Daw@inl.gov, 208-526-7114; Bernhard R. Tittmann, Penn State University, brt4@psu.edu, 814-865-7827.
Irradiation and Signal Processing Enhancements project because it will enable in-core use of ultrasound-based sensors that are uniquely capable of meeting DOE program enhanced instrumentation needs.

Ultrasonic measurements have a long and successful history of use for materials characterization, including detection and characterization of degradation and damage, measurement of various physical parameters used for process control, such as temperature and fluid flow rate, and in non-destructive evaluation (NDE) [7]. Ultrasonic measurements have been demonstrated to measure successfully fission gas release [8], used for under sodium viewing [9] for fuel porosity measurements [10,11], and for thermometry [12]. However, application of ultrasonic sensors in nuclear reactors has been limited to low neutron flux environments [1].

There is surprisingly little literature available on the effects of neutron irradiation on piezoelectric and magnetostrictive transduction. A review paper on the radiation endurance of piezoelectric transducers by Sinclair and Chertov only lists six piezoelectric materials, few of which have been exposed to a sufficiently high enough neutron fluence to replicate commercial power water reactor environments [13]. We aim, in this study, to extend the number of piezoelectric and magnetostrictive materials studied and to present a method for characterizing their performance during an instrumented lead test.

In this study, three piezoelectric and two magnetostrictive materials were instrumented and placed in the Massachusetts Institute of Technology's (MIT) Nuclear Reactor. The piezoelectric materials chosen were Aluminum Nitride, Zinc Oxide and Bismuth Titanate and the magnetostrictive materials chosen were Remendur and Galfenol. The reasons for choosing these materials are explained in their respective sections.

\section{METHOD}

\section{A. Piezoelectric Sensor Design}

The development of ultrasonic tools to perform different inpile measurements requires a fundamental understanding of the behavior of ultrasonic-transducer materials in these high neutron flux environments. Many piezoelectric materials have been tested without much success. For instance, at fluence near $10^{18} \mathrm{n} / \mathrm{cm}^{2}$, PZT develops anti-ferroelectric properties [14] and Barium Titanate undergoes a phase transition [15]. Although some of the high temperature single crystals such as quartz or gallium phosphate looked like promising materials, amorphization of the bulk material is problematic. For 
instance, quartz has been shown to degrade at fluences of approximately $9 \times 10^{19} \mathrm{n} / \mathrm{cm}^{2}$ due to amorphization of domains, as measured by $\mathrm{x}$-ray spectroscopy $[16,17]$.

However, some materials have shown promise. Thin film AlN has been shown to be unaffected by gamma irradiation up to 18.7 MGy [9] and temperatures up to $1000^{\circ} \mathrm{C}[18,19]$. Moreover, this material has been explicitly cited in numerous independent studies as a highly radiation tolerant [20]. Tests of bulk single crystal AlN in a TRIGA nuclear reactor core showed this material to be completely unaffected by a fast and thermal neutron fluence of $1.85 \times 10^{18} \mathrm{n} / \mathrm{cm}^{2}$ and $5.8 \times 10^{18}$ $\mathrm{n} / \mathrm{cm}^{2}$ respectively and a gamma dose of $26.8 \mathrm{MGy}$ [21].

Zinc oxide has one of the strongest piezoelectric electromechanical coupling factors $\left(\mathrm{k}_{33}\right)$ of the tetrahedrally bonded semiconductors, such as GaN and AlN, mostly because the clamped-ion and internal strain contributions do not cancel each other out as substantially [22]. It has an electro-mechanical coupling coefficient of approximately 0.48 while aluminum nitride has a coupling coefficient of approximately 0.3 . This is in-part due to the higher piezoelectric coupling coefficient $\left(\mathrm{d}_{33}\right)$. Zinc Oxide's $\mathrm{d}_{33}$ is approximately $12.4 \mathrm{pC} / \mathrm{N}$, while aluminum nitride's is approximately $5 \mathrm{pC} / \mathrm{N}$ [23].

There is little literature on zinc oxide's transduction capabilities in a radiation environment. However, like AlN, the strong ionic bonding of $\mathrm{ZnO}$ is thought to provide a high resistance to amorphization [2]. A fast neutron $(1 \mathrm{MeV})$ is capable of delivering $59 \mathrm{keV}$ to a zinc primary knock-on-atom or $221 \mathrm{keV}$ to an oxygen primary knock-on-atom. This is sufficient energy to displace either atom from their lattice position with similar energies to $\mathrm{keV}$ ion implantations. However, during an irradiation of approximately $1.0 \times 10^{19}$ $\mathrm{n}_{\mathrm{f}} / \mathrm{cm}^{2}$ only a slight change in lattice parameters was observed ( $\mathrm{a}=0.03 \%$ decrease and $\mathrm{c}=0.04 \%$ increase) as well as blistering to the specimens surface [24].

Of the pervoskyte type ceramics bismuth titanate is thought of as the likeliest candidate to perform well in a high neutron flux environment. Kazys has exposed bismuth titanate to 22.7 MGy dose from a ${ }^{60} \mathrm{Co}$ source with only a moderate decrease in pulse-echo amplitude (4\%) [9]. Although the phase transition at $650{ }^{\circ} \mathrm{C}$ is unfavorable for thermal spike damage, bismuth titanate has a higher $\mathrm{d}_{33}$ than both AlN and $\mathrm{ZnO}$. Although it may not survive as long as single crystal ceramics, it could be utilized for environments with a lower neutron flux, while providing increased sensitivity.

The piezoelectric sensors were constructed from a stainless steel 218 housing, stainless steel 304 cap, alumina insulation; nickel lead electrode, carbon-carbon backing, kovar or aluminum 6061 waveguide, and a high temperature spring. The active element was bonded to the kovar waveguide, in the case of the aluminum nitride sensors, using a high temperature ceramic (Aremco Products, Inc.), and, in the case of the zinc oxide and bismuth titanate sensors, using $99.99 \%$ pure aluminum foil, Fig. 1.

\section{B. Magnetostrictive Sensor Design}

The magnetostrictive transducer materials were selected



Fig. 1. Design of piezoelectric capsule. The components are: (1) outer Casing, (2) cap (3) high temperature spring, (4) waveguide, (7) backing, (9) plunger, (10), (11) and (12) insulation. The piezoelectric element was placed between the backing (7) and the waveguide (4) using either foil or a bonding agent.

based on previous use in radiation environments, amounts of neutron sensitive materials, Curie temperatures, and saturation magnetostriction. Remendur has the most history of use in nuclear applications of all the magnetostrictive alloys, having been used previously for short duration thermometry applications. Remendur has a high Curie temperature $\left(950{ }^{\circ} \mathrm{C}\right)$ and relatively high saturation magnetostriction ( $\sim 70 \mu$ strains). Remendur is an alloy composed of approximately $49 \%$ iron, $49 \%$ cobalt, and $2 \%$ vanadium. Because of its cobalt content, Remendur was not considered to be an ideal choice (due to concerns about the production of Cobalt-60 during irradiation). However, its successful prior use was deemed sufficient reason to warrant inclusion.

Galfenol is a relatively new alloy of iron and gallium (approximately 13\% gallium). Galfenol is a member of the "giant" magnetostrictive alloys and has a very large saturation magnetostriction (100-400 $\mu$ strains). It also has an appropriately high Curie temperature $\left(700^{\circ} \mathrm{C}\right)$. Neither of its constituent elements reacts strongly with neutron radiation. These factors made Galfenol the most appealing magnetostrictive material candidate.

Arnold Magnetics produces several magnetostrictive alloys, Arnokrome 3, Arnokrome 4, and Arnokrome 5. Arnokrome 3 contains cobalt, has much lower magnetostriction than Remendur, and is therefore not of interest in the current study. Arnokrome 4 and 5 have similar magnetostriction to Arnokrome 3, but without the presence of cobalt. Due to space limitations and the availability of these alloys only as sheets/strips, Arnokrome was included as stand-alone samples in the test capsule but not incorporated into transducers. These samples were evaluated in the Post Irradiation Examinations (PIE) program.

The magnetostrictive transducers selected for this test is based on research by Lynnworth [25] and Daw [12]. The magnetostrictive transducers consist of a small driving/sensing coil, a biasing magnet, and a magnetostrictive waveguide. The ultrasonic signal is generated when a high frequency alternating current pulse is driven through the coil. The induced magnetic field causes magnetic domains within the material to oscillate. The domains are pre-biased by the magnet to maximize the response. During initial testing of 


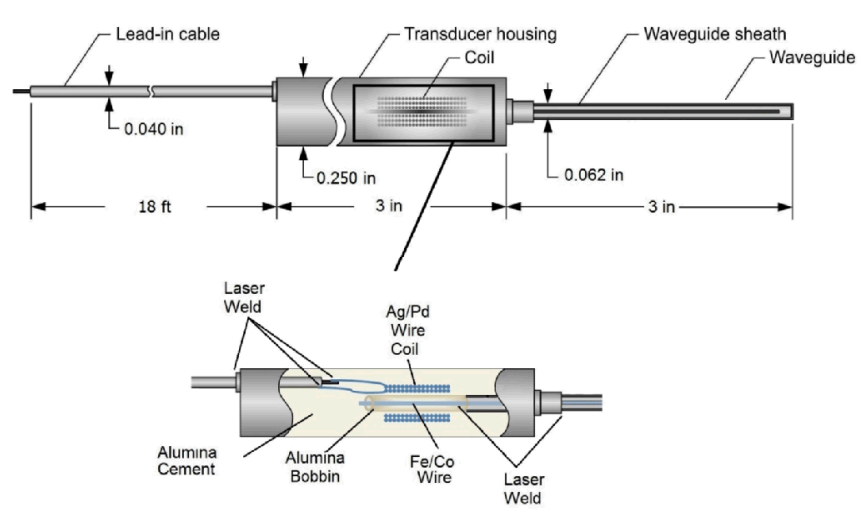

Fig. 2. Schematic diagram of magnetostrictive transducer with internal components.

prototype magnetostrictive transducers, it was discovered that an initial heat treat of the magnetostrictive wire, under ultrasonic pulsing, improved the performance of the transducer enough to eliminate the need for a magnet. This is important, as the magnets with high enough Curie temperatures for in-core use typically have large amounts of Cobalt. Received echoes are detected through the reciprocal effect. A schematic of the magnetostrictive transducer design is shown in Fig. 2.

\section{Capsule Design}

A specimen fixture was machined from graphite and clad with titanium. In it, were four piezoelectric sensors, two magnetostrictive sensors, two K-type thermocouples, a neutron flux detector, and a gamma flux detector. Each of these devices was fitted with a $1 \mathrm{~mm}$ outer diameter, mineral insulated coaxial cable (Thermocoax Inc., Suresnes, France). The cable was constructed with a stainless steel $304 \mathrm{~L}$ outer sheath, a copper inner sheath, silicon dioxide insulation, and a copper inner lead wire. There were a total of ten cables each approximately 18 feet long. They were connected to a $50 \Omega$ impedance junction box at the top of the reactor and to each of the respective sensors through a strain relief at the top of the capsule.

In addition to the active and passive sensors were five melt wires encapsulated in quartz, with melt temperatures ranging from 327 to $514{ }^{\circ} \mathrm{C}$, Fe-Ni-Cr flux wires in various positions in the capsule, and spare active elements Galfenol, Remendur, $\mathrm{AlN}$, and BiT. The capsule and each of the respective components is shown in Fig. 3. Although a part of the experimental setup, the magnetostrictive sensors will not be discussed further.

\section{In Core Sample Assembly}

The irradiation of the chosen sensor materials was conducted at the MIT nuclear reactor, being inserted in-core. The MIT reactor is a light-water cooled and moderated, heavy-water reflected, nuclear reactor. The reactor uses $\mathrm{UAl}_{\mathrm{x}}$ cermet clad with Al 6061 designed in a rhombohedral shape, producing neutron flux rates for the sensors position given in Table I [26].

The in-core sample assembly (ICSA) consisted of a titanium tube in contact with the primary water on its outside

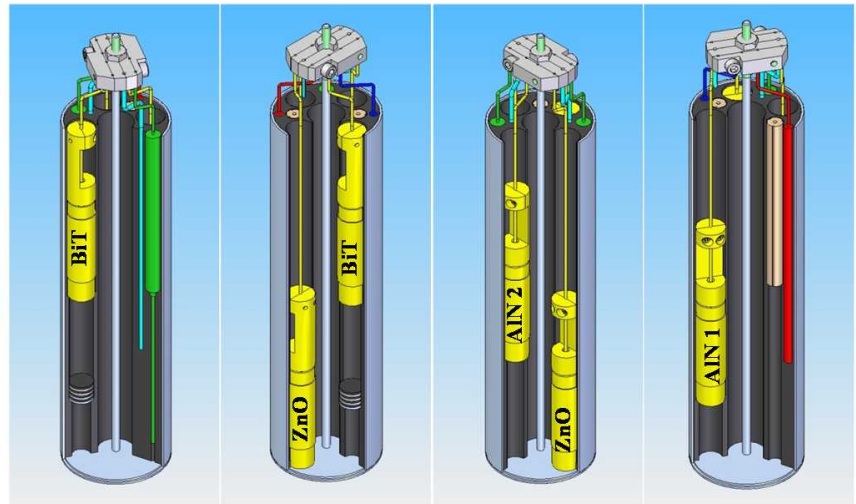

Fig. 3. 3D Renderings of the ULTRA-capsule as constructed for the irradiation. The piezoelectric sensors are shown in yellow, the magnetostrictive sensors are shown in green, the piezoelectric drop in specimens are shown as gray disks, while the magnetostrictive drop-in samples are shown in a peach cylinder.

surface, originating at the reactor head and extending into the reactor core. The internal space (about $5 \mathrm{~cm}$ in diameter) was filled with inert gasses, helium and neon, that were injected at variable mass flow rates at the bottom of the core and removed at the top. Flow rates were adjusted to control the temperature of the sensor capsules.

A 15.24 meter RG 58 low loss coaxial cable connected to the $50 \Omega$ junction box and an NI-PXI 1042 chassis through PXI-2593 switch cards. The switch card was connected to the NDT-5800 PR pulser/receiver and a SMX-2064 Digital Multimeter. This enabled either DC impedance measurements or pulser/receiver measurements. The settings used for the pulser/receiver are saved alongside each of the waveforms in an associated file. The pulser/receiver was connected to a ZTEC ZT4211 digital oscilloscope.

A LabVIEW program was designed so that periodic measurements could be made on each of the transducers connected to the switch board. The data output was organized by transducer and tagged with the acquisition date and time so that acoustical data could be correlated with external sensor measurements such as neutron power or temperature. The sample rate was initially one measurement every thirty minutes, but was increased to one measurement every two hours after the reactor reached its first power cycle.

The magnetostrictive transducers were connected via RG 58 coaxial cable to a USUltratek EUT3160M2T tone-burst capable Ethernet pulser/receiver system, which was set to continually interrogate the transducers. As with the piezoelectric transducers, a LabVIEW program was developed to record the time response of the magnetostrictive transducers. A-scan signals were recorded for each magnetostrictive transducer every two hours. The recorded signals were then analyzed in Matlab. The amplitude of the first reflected acoustic signal was used to monitor performance over the course of the irradiation.

\section{E. Overview of Irradiation}

The ULTRA capsule was inserted into the reactor on February 18th 2014 and removed on May 12th 2015. The samples were in the reactor for a total of 449 days before they 
were moved to the hot cell for post irradiation analysis. The capsule rode along the reactors normal operation and as such was subjected to periodic shutdowns. The neutron fluence reached $1.877 \times 10^{21} \mathrm{n} / \mathrm{cm}^{2}$, for neutrons with energy greater than $0.1 \mathrm{MeV}$, and $8.68 \times 10^{20} \mathrm{n}_{\mathrm{f}} / \mathrm{cm}^{2}$, for neutrons with energy greater than $1 \mathrm{MeV}$. The max gamma exposure was approximately $7.23 \times 10^{21} \mathrm{gamma} / \mathrm{cm}^{2}$.

\section{RESULTS}

\section{A. Aluminum Nitride}

One of the aluminum nitride sensors survived until the very end of the experiment, while the other failed due to an electrical short. The A-scan from the first day following insertion and the last measurement made during the irradiation is plotted in Fig. 4(a). The last measurement clearly shows a longer ring down than the first measurement as well as generally lower signal to noise ratio. Although the first and second echoes of the last A-scan are not resolvable, the third and fourth echoes are distinct.

A comparison of the third echoes is shown in Fig. 4(b). There is a reduction in the pulse-echo amplitude, coupled with a $6.7 \%$ reduction in the center frequency, and $14 \%$ increase in bandwidth. Comparing the fourth echoes before and after the experiment, there was a $57 \%$ reduction in the peak amplitude.

After the irradiation the capsule was disassembled and optical inspections revealed that the backing material had delaminated from the surviving AlN sensor, which might account for the change in quality factor. Also, the sensor changed from a milky white before the irradiation to black

TABLE I

OVERVIEW OF NEUTRON FLUX ENERGY SPECTRUM

\begin{tabular}{lll}
\hline \hline \multicolumn{1}{c}{ Unit: $\mathrm{n} / \mathrm{cm}^{\wedge} 2 / \mathrm{s}$} & Flux @ 5.8 MW & \multicolumn{1}{c}{ Flux/MW } \\
\hline Thermal Flux $(<0.4 \mathrm{eV})$ & $2.12 \mathrm{E}+13(11.2 \%)$ & $3.66 \mathrm{E}+12$ \\
Epi-thermal flux $(0.4 \mathrm{eV}$, & $8.03 \mathrm{E}+13(42.4 \%)$ & $1.38 \mathrm{E}+13$ \\
$0.1 \mathrm{MeV})$ & & \\
Fast flux 1 $(>0.1 \mathrm{MeV})$ & $8.78 \mathrm{E}+13(46.4 \%)$ & $1.51 \mathrm{E}+13$ \\
Fast flux 2 (>1.0 MeV) & $4.05 \mathrm{E}+13(21.4 \%)$ & $6.98 \mathrm{E}+12$ \\
Total (Full Range) & $1.89 \mathrm{E}+14(100 \%)$ & $3.26 \mathrm{E}+13$ \\
\hline \hline
\end{tabular}

after the irradiation. Further, $d_{33}$ measurements made on the AlN drop-in sample were in approximately $2.9 \pm .2 \mathrm{pC} / \mathrm{N}$.

Due to changes in coupling of the active element and the waveguide as a function of reactor power, measurements could only be made while the reactor was off. The change in coupling occurred early in the irradiation, which optical inspection after the test indicates was a delamination of the active element from the waveguide,

Fig. 5 shows selected A-scans during the irradiation. It is assumed that the initial decrease in pulse-echo amplitude is a result of the delamination. An echo from the back wall of the waveguide was identified and measured to determine the performance of the $\mathrm{ZnO}$ sensor during the irradiation. At the end of the experiment no pulse-echo amplitude was measured. Because the pulse-echo amplitude could only be measured when the reactor was off, the sensor is considered to have failed at $6.27 \mathrm{E}+20 \mathrm{n}_{\mathrm{f}} / \mathrm{cm}^{2}$ just before the last power cycle. It is unclear what caused the failure; however, the DC resistance was $120 \Omega$, when it should have been several $\mathrm{M} \Omega$.

After taking the sensor capsule apart it was clear that the active element had delaminated from the waveguide and that it had changed from a milky clear color to an orange color. Unfortunately the sensor was too radioactive to take out of the hot box to measure its material properties.

\section{B. Bismuth Titanate}

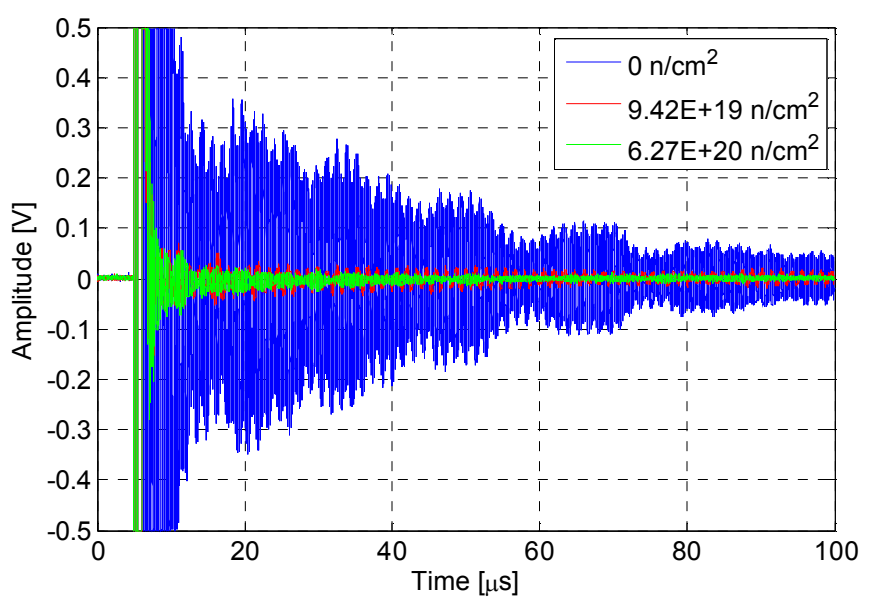

Fig. 5. A-scans from the $\mathrm{ZnO}$ sensors for selected fluence levels during the irradiation. In all cases the reactor was off.

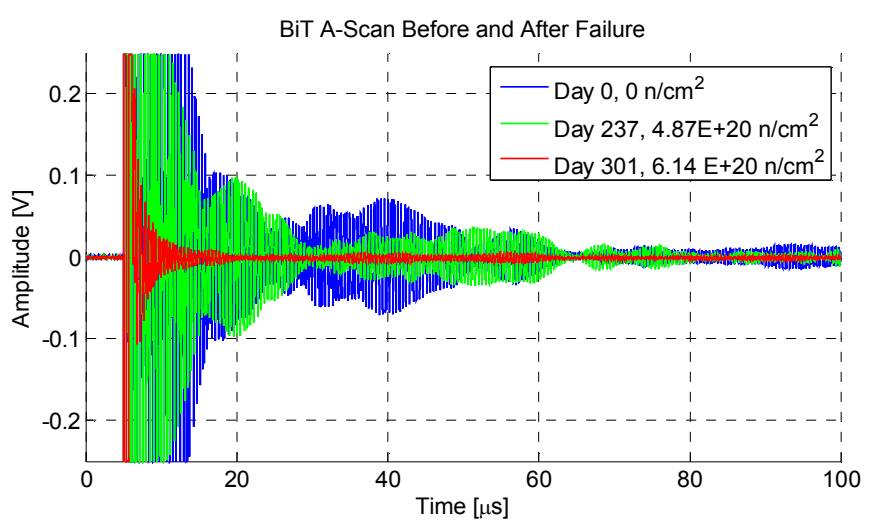

Fig. 6. Comparison of A-scans from day 1, 237, and 301 from BiT sensor. These represent A-scans from before and after failure of the sensor. 
In these experiments, Bismuth Titanate has been demonstrated to operate up to a fast neutron fluence of $5 \mathrm{E}+20$ $\mathrm{n} / \mathrm{cm}^{2}$. This was preceded by fairly large fluctuations in amplitude, as much as $20-40 \%$. There was an initial decline in the amplitude of the fundamental harmonic starting on day 10 or at $1.28 \mathrm{E}+19 \mathrm{n} / \mathrm{cm}^{2}$ and reaching a minimum relative amplitude of $60 \%$ at $5.29 \mathrm{E}+19 \mathrm{n} / \mathrm{cm}^{2}$ on day 25 . The amplitude gradually recovered to relative amplitude of $100 \%$ at $1.1 \mathrm{E}+20 \mathrm{n} / \mathrm{cm}^{2}$. The sensor failure is noted by a significant decrease in the fundamental amplitude after $5 \mathrm{E}+20 \mathrm{n} / \mathrm{cm}^{2}$. This decline occurred over a period of 17 days, dropping in amplitude by $80 \%$. There was no notable recovery during this period; however, an echo from the back wall of the waveguide was still measureable. At the end of the irradiation the DC impedance was measured to be $11 \mathrm{k} \Omega$. Further, the $\mathrm{d}_{33}$ was $11.5 \pm 1.5 \mathrm{pC} / \mathrm{N}$, measured from the drop-in sample after the irradiation. The $\mathrm{d}_{33}$ as reported by the material supplier, TRS Technologies, is $20 \mathrm{pC} / \mathrm{N}$.

\section{Remendur}

Fig. 7 shows the normalized amplitude for the Remendur transducer as a function of accumulated fluence. The green trace corresponds to the reactor power and gives an idea of temperature. The maximum power of $5.8 \mathrm{MW}$ corresponds to a temperature of roughly $450{ }^{\circ} \mathrm{C}$. There is a general decreasing trend to the amplitude, but signal recovery after temperature transients indicates that some of the signal attenuation is likely due to temperature effects, in this case binding of the wire against the coil bobbin (see Fig. 2 for transducer component diagram). Increased noise after the reactor was restarted after

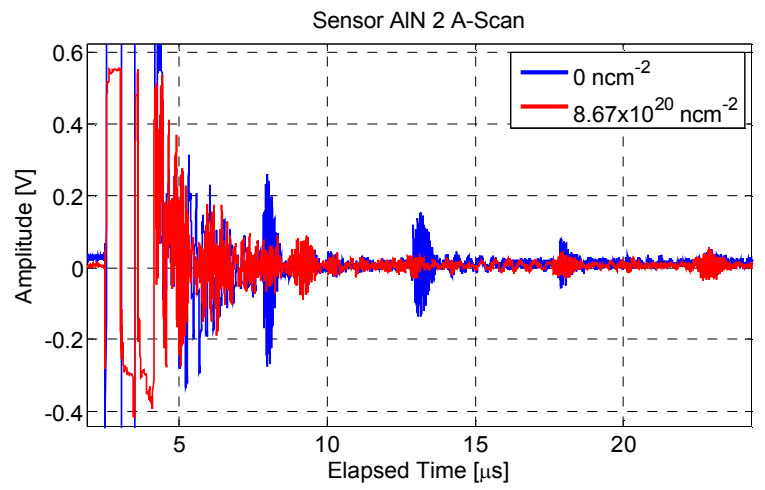

(a)

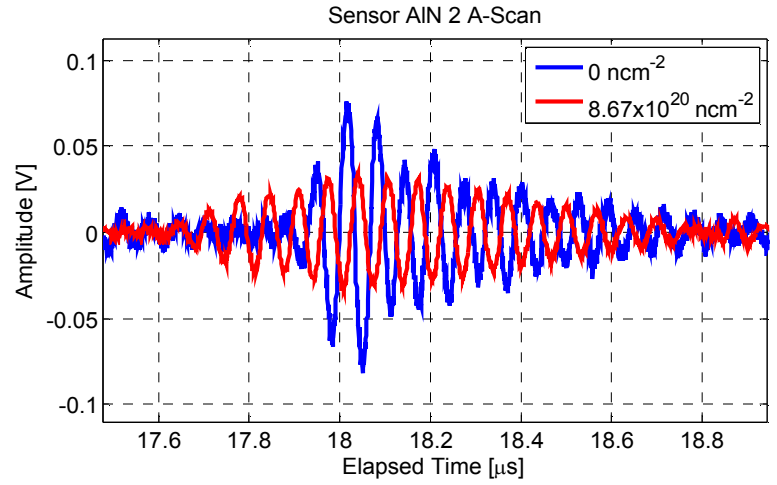

(b)

Fig. 4. (a) Comparison of A-scans before and after irradiation. (b) Comparison of third echo in A-scans before and after irradiation.

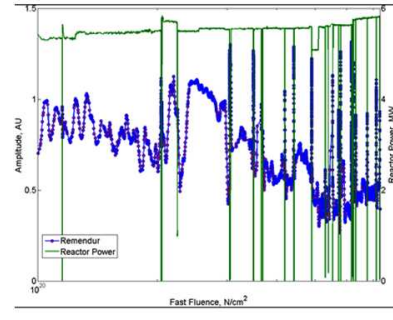

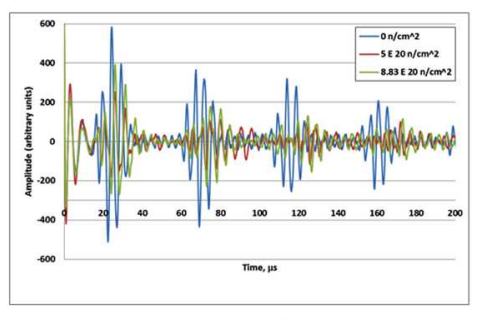

b.
Fig. 7. Performance data for the Remendur magnetostrictive transducer. Figure 7a shows signal amplitude with respect to fluence and Figure $7 \mathrm{~b}$ shows selected A-scan waveforms.

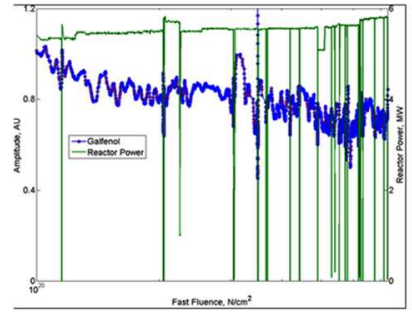

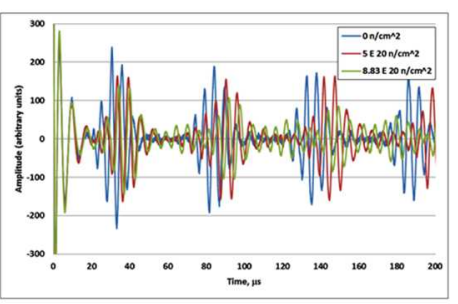

b.
Fig. 8. Performance data for the Galfenol magnetostrictive transducer. Figure $8 \mathrm{a}$ shows signal amplitude with respect to fluence and Figure $8 \mathrm{~b}$ shows selected A-scan waveforms.

refueling may indicate an intermittent short in the drive/sense coil, likely caused during removal of the in-core tube during refueling. Tests conducted during post irradiation examination were performed to compare the pulse-echo amplitude of an irradiated sample of Remendur to an un-irradiated sample. Manual placement of the sample within a test coil made recording of the A-scans difficult, as the signal amplitude is very sensitive to positioning, but no significant differences in signal strength were observed.

\section{Galfenol}

The Galfenol transducer has shown very stable operation over the course of the irradiation, though the total peak to peak signal amplitude is typically on the order of one third of that observed for Remendur. Fig. 8a shows the amplitude of the first A-scan echo as a function of fluence. The green trace shows the reactor power and gives an idea of temperature. The maximum power of $5.8 \mathrm{MW}$ corresponds to a temperature of roughly $450{ }^{\circ} \mathrm{C}$. Fig. $8 \mathrm{~b}$ shows selected A-scans during the irradiation. The Galfenol transducer exhibited steady operation during periods when the reactor power level was stable. There was little decrease in the signal strength over these periods. The decreases in signal strength observed when reactor power is increased appear to be due to increases in operating temperature, as the signal strength stabilizes shortly after each power increase. Tests conducted during post irradiation examination were also performed to compare the pulse-echo amplitude of an irradiated sample of Galfenol to an unirradiated sample. As with the Remendur, manual placement of the sample within a test coil made recording of the A-scans difficult, as the signal amplitude is very sensitive to positioning, but no significant differences in signal strength were observed. 


\section{CONCLUSIONS}

Acoustic measurements indicated that all of these sensors were able to transduce during the irradiation. The bismuth titanate sensor began to degrade in performance and failed at approximately $5 \times 10^{20} \mathrm{n} / \mathrm{cm}^{2}$. This failure was gradual, occurring over a period of several weeks. This failure is suspected to be a result of the irradiation and is consistent with a reduction in remnant polarization. Further, measurements on a bismuth titanate sample, riding along with the experiment, showed a $50 \%$ decrease in $d_{33}$. This supports the conclusion that the remnant polarization had decreased.

The zinc oxide sensor was temperamental throughout the entire experiment. The sensor was only capable of transduction during the reactor off cycles making characterization of its pulse-echo amplitude difficult. However, it is clear that the sensor was capable of transduction up to approximately $6.27 \times 10^{20} \mathrm{n} / \mathrm{cm}^{2}$. At this point, the reactor turned on and measurements were only obtainable at the end of the experiment. At the end of the irradiation the sensor was pulsed and no acoustic data was measured. It is not known if the failure was due to material property changes in the $\mathrm{ZnO}$ or if there was a failure in the construction of the sensor. It should be noted that the $\mathrm{ZnO}$ had changed in color.

Lastly, the aluminum nitride sensor, by far, performed the best. The sensor was capable of transduction throughout the entire irradiation. Although the report pulse-echo amplitude is reported to decrease by $57 \%$, this measure is not consistent when measuring each of the echoes. When considering the fourth echo, the drop in pulse-echo amplitude is only $12 \%$. This leaves considerable future work in improving the signal processing algorithms used to analyze the acoustic signals.

Although a significant progress has been achieved, more work needs to be done, for example optical and acoustical inspections need to be completed. However, numerous impedance and microstructural measurements can be made at facilities such as Idaho National Labs. These measurements help develop constitutive models to describe the evolution of mechanical and electrical properties of the active element while subject to similar neutron fluxes.

Due to their low operating frequencies (100's of kilohertz), the magnetostrictive transducers are not promising for as wide a variety of applications as the piezoelectric transducers. But results of this irradiation test indicate that transducers fabricated using magnetostrictive alloys (Galfenol, in particular) are very tolerant to neutron and gamma radiation effects and would be good candidates for in-core use in some targeted applications, such as thermometry.

\section{REFERENCES}

[1] J. Rempe, H. MacLean, R. Schley, D. Hurley, J. Daw, S. Taylor, J. Smith, J. Svoboda, D. Kotter, D. Knudson, S. C. Wilkins, M. Guers, L. Bond, L. Ott, J. McDuffee, E. Parma and G. Rochau, "New In-Pile Instrumentation to Support Fuel Cycle Research and Development," FCRD-FUEL-2011-000033, 2011
[2] K. Natesan, S. Majumdar, R. K. Nanstad and T. L. Sham, "Code Qualification of Structural Materials for AFCI Advanced Recycling Reactors," ANL-AFCI-244, 2008.

[3] "Light Water Reactor Sustainability Program Integrated Program Plan," INL/EXT-11-23452, 2012.

[4] N. K, S. Majumdar, P. S. Shankar and V. N. Shah, "Prelimenary Materials Selection Issues for the Next Generation Nuclear Plant Reactor Pressure Vessel," ANL/EXT-06/45, 2006.

[5] K. Maeda, S. Sasaki, M. Kato and Y. Kihara, "Radial redistribution of actinides in irradiated FR-MOX fuels," J. Nucl. Mater, vol. 389, pp. 7884, 2009.

[6] N. Chauvin, A. Courcelle, M. Pelletier, Y. Guerin, J. Escleine, M. Phelip, F. Michel, S. Bejaoui and M. Lainet, "Fuel Design, Irradiation Programme and Modelling, Applications to Several Fuels for BENIV Systems," in ATR NSUF User's Weel, 2010.

[7] P. J. Shull and R. B. Tittmann, "Ultrasound," in Nondestructive Evaluation, New York, Marcel Dekker, Inc., 2001, pp. 63-192.

[8] J. F. Villard and M. Schyns, "Advanced in-pile measurements of fast flux, dimensions, and fission gas release," Nuclear technology, vol. 173, no. 1, pp. 86-97, 2011.

[9] R. Kazys, A. Voleisis, R. Sliteris, B. Voleisiene, L. Mazeika and H. A. Abderrahim, "Research and development of radiation resistant ultrasonic sensors for quasi-image forming systems in a liquid lead-bismuth," Ultragarsas Journal, vol. 62, no. 3, 2007.

[10] K. Phani, S. Nitogi, A. Maitra and M. Roychaudhury, "Strength and elastic modulus of a prous brittle solid: an acousto-ultrasounic study," $J$. Mater. Sci, vol. 21, pp. 4335-4341, 1986.

[11] K. Phani, D. Sanyal and K. Sengupta, "Estimation of elastic properties of nuclear fuel material using longitudinal ultrasonic velocity - A new approach," J. Nucl. Mater, vol. 366, no. 1-2, pp. 129-136, 2007.

[12] J. Daw, J. Rempe, S. Taylor, J. Crepeau and S. Wilkins, "Ultrasonic Thermometry for In-Pile Temperature Detection," in Seventh American Nuclear Society International Topical Meeting on Nuclear Plant Instrumentation, Control and Human-Machine Interface Technologies, Las Vegas, Nevada, 2010.

[13] A. N. Sinclair and A. M. Chertov, "Radiation endurance o piezoelectric ultrasonic transducers," Ultrasonics, vol. 57, pp. 1-10, 2015.

[14] D. Glower, D. Hester and D. Warnke, "Effects of Radiation-Induced Damage Centers in Lead Zirconate Titanate Ceramics," Journal of The American Ceramic Society, vol. 48, no. 8, pp. 417-421, 1981.

[15] D. Glower and D. Hester, "Hysteresis Studies of Reactor Irradiation Single-Crystal Barium Titanate," Journal of Applied Physics, vol. 36, no. 7, p. 2175, 1965.

[16] K. Abdukadryova, "Investigation of radiation damage in neutronirradiated quartz," Atomic Energy, vol. 85, no. 1, 1998.

[17] J. P. Bonnet, M. Boissier and A. A. Gherbi, "The amorphization process of neutron-irradiated crystalline quartz studied by Brillouin scattering," Journal of Non-Crystalline Solids, vol. 167, no. 1-2, pp. 199-204, 1994.

[18] N. D. Patel, S. X. Fullord and P. S. Nicholson, "High Frequency-High Temperature Ultrasonic Transducers," in Review of Progress in Quantitative Nondestructive Evaluation, 1990.

[19] D. A. Stubbs and R. E. Dutton, "An Ultrasonic Sensor for HighTemperature Materials Processing," JOM, vol. 48, no. 9, pp. 29-31, 1996.

[20] K. Trachenko, "Understanding resistance to amorphization by radiation damage," J. Phys. Condens. Matter, vol. 16, pp. R1491-R1515, 2004.

[21] D. Parks, "Development of a piezoelectric ultrasonic array sensor for nuclear reactor applications," (Thesis) The Pennsylvania State University, 2012.

[22] A. Dal Corso, M. Posternak, R. Resta and A. Baldereschi, "Ab initio study of piezoelectricity and spontaneous polarization in $\mathrm{ZnO}$," Physical Review B, vol. 50, no. 15, 1994

[23] O. E. Mattiat and D. Berkincourt, "Piezoelectric Crystals and Ceramics," in Ultrasonic Transducer Materials, New York, Plenum Press, 1971.

[24] K. Lorenz, M. Peres, N. Franco, J. G. Marques, S. M. C. Miranda, S. Magalhaes, T. Monteiro, W. Wesch, E. Alves and E. Wendler, "Radiation damage formation and annealing in $\mathrm{GaN}$ and $\mathrm{ZnO}$," in Proc. of SPIE, 2011.

[25] L. Lynworth, E. Carnevale, M. McDonough and S. Fam, "Ultrasonic Thermometry for Nuclear Reactors," IEEE Transactions on Nuclear Science, vol. 16, no. 1, pp. 184-187, 1969.

[26] D. Carpenter, G. Kohse and L.-w. Hu, "MITR Users' Guide," 2012. 


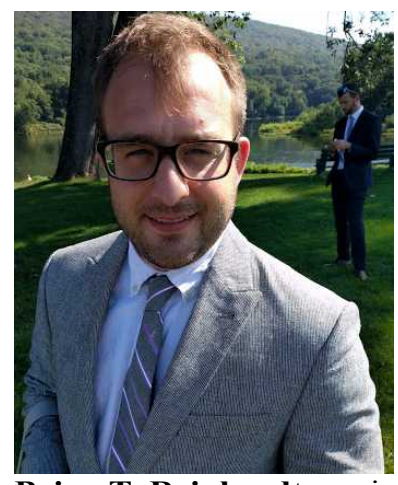

Brian T. Reinhardt received his Ph. D from the Pennsylvania State University in 2016, in Engineering Science and Mechanics. In 2010 he spent six months in Japan working for Hitachi, Ltd working on nonlinear contact mechanics. He cofounded of Lasers for Innovative Solutions, LLC in 2012 and currently works for the Applied Research Labs at Penn State.

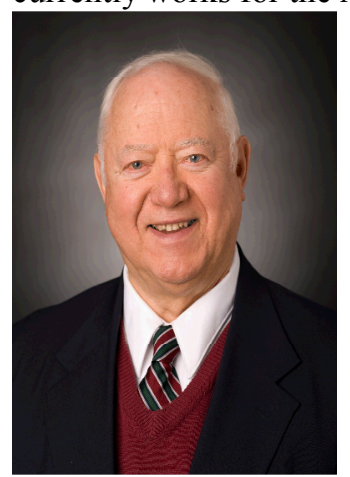

Bernhard R. Tittmann (M'76-F'90) entered the University of California at Los Angeles as a Howard Hughes Fellow and got his Ph.D. in 1965 from UCLA.

He joined the North American Science Center in 1966 where he remained until 1989 as the manager of the Materials Evaluation Group. Since then he was appointed as the chair of the Schell Professor of Engineering at Penn State University in the Department of Engineering Science and Mechanics at the Pennsylvania State University, University Park, Pennsylvania. 